\title{
D. PEDRO II, MONARCA-TRADUTOR
}

\author{
Marcia Amaral Peixoto Martins ${ }^{1}$ \\ Anna Olga Prudente de Oliveira ${ }^{2}$
}

\begin{abstract}
RESUMO: A proposta deste artigo é contribuir para a história da tradução no Brasil, investigando a atuação tradutória de D. Pedro II, Imperador do Brasil de 1831 a 1889. Buscou-se mapear sua produção nessa área, determinar seus objetivos ao traduzir, suas ideias acerca da tradução, as estratégias tradutórias adotadas e, na medida do possivel, identificar relações ou topicalidades entre a seleção dos textos selecionados para tradução e situações, períodos ou ideais políticos.
\end{abstract}

UNITERMOS: reis tradutores; D. Pedro II; historiografia da tradução; tradução de poesia.

ABSTRACT: The aim of this article is to contribute to the history of translation in Brazil by investigating the translations made by Dom Pedro II, Emperor of Brazil from 1831 to 1889. The study focused on his translations in an attempt to understand his reasons for translating, his views on translation, the translation strategies he resorted to and possible links between the selection of texts selected for translation and political situations, periods or ideals.

KEYWORDS: royal translators; Emperor Pedro II of Brazil; historiography of translation; poetry translation.

PUC-Rio.mmartins@puc-rio.br PUC-Rio. annaolga@terra.com.br 


\section{Introdução}

Em diversas épocas, soberanos com sólida formação humanística se voltaram para a tradução, seja traduzindo propriamente, seja incentivando a atividade tradutória. Podiam ter como objetivo a transmissão de um patrimônio literário aos súditos, a disseminação de conhecimento científico, a afirmação de uma identidade nacional por meio do fortalecimento do respectivo vernáculo, ou simplesmente o exercício de habilidades linguísticas. Entre esses monarcas, destacam-se Alfredo, o Grande (849-899), rei de Wessex, tradutor de obras do latim para o inglês, como Cura pastoralis, do papa Gregório I, e De Consolatione Philosophiae, de Boécio; Afonso X, o Sábio (12211284), rei de Leão e Castela, patrono da chamada Escola de Tradução de Toledo; e D. Luís I de Portugal (1838-1889), tradutor de Shakespeare.

No Brasil, o imperador Pedro II (1825-1891), conhecido por sua erudição, foi um grande mecenas das artes e da ciência. Voltou-se especialmente para o aprendizado de idiomas, tendo estudado pelo menos doze. Embora também tenha se dedicado à tradução, até o momento há poucas pesquisas a respeito dessa atividade exercida pelo monarca brasileiro.

Com o objetivo de preencher essa lacuna e contribuir para a história da tradução no Brasil, investigamos a atuação tradutória de D. Pedro II, buscando mapear sua produção nessa área, determinar seus objetivos ao traduzir, suas ideias acerca da tradução, as estratégias tradutórias adotadas e, na medida do possivel, identificar relações ou topicalidades entre a seleção dos textos selecionados para tradução e situações, períodos ou ideais políticos. Analisamos biografias e artigos que mencionam a atividade tradutória do imperador e procuramos localizar os textos traduzidos, tarefa bastante complexa, visto que a maioria deles não se encontra publicada ou disponivel em meio digital.

\section{O erudito imperador dos trópicos}

D. Pedro II, imperador do Brasil de 1831 a 1889, começou a governar em 1840 , aos 14 anos, quando teve sua maioridade 
decretada. Com a proclamação da República, foi deposto e exilado, aos 65 anos. Durante o período da Regência, sua educação ficou a cargo de tutores. O primeiro foi José Bonifácio de Andrada e Silva, escolhido por D. Pedro I antes de abdicar, e que só permaneceu na função de 1831 a 1833. Seu sucessor no cargo foi Manuel Inácio de Andrade Souto Maior Pinto Coelho, futuro marquês de Itanhaém, que estabeleceu regras rígidas para a educação do imperador e o manteve distante da realidade fora do palácio. O ideal de educação de Itanhaém era formar um monarca completo, que seguisse preceitos humanistas, e para isso elaborou um regulamento que deveria ser seguido por todos os mestres. D. Pedro II obedecia a uma rotina rígida, que exigia disciplina e pontualidade, hábitos incorporados em sua vida adulta (Carvalho, 2007). Para ele, o estudo sempre foi uma grande paixão, a ponto de escrever em seu diário: "Nasci para consagrar-me às letras e às ciências. O estudo, a leitura e a educação de minhas filhas [...] são meus principais divertimentos" (Olivieri, 1999: 25).

Desde cedo demonstrou especial interesse por idiomas, tendo estudado grego, latim, inglês, francês, italiano, provençal, alemão, tupi, guarani, hebraico, sânscrito e árabe com mestres como Félix Emílio Taunay, diretor da Academia Imperial de Belas Artes, professor de grego; Leonard Akerbloom, cônsul da Suécia no Rio de Janeiro, professor de hebraico; e o Barão de Schreiner, ministro da Áustria no Brasil, professor de árabe. Bastante precoce, aos 12 anos já falava e escrevia francês e lia e traduzia inglês; aos 14, "compunha e vertia latim sem erros, deixando as poucas brincadeiras para só ler e estudar" (Carva1ho, 2007: 30). A imagem pública de amigo dos livros, que o acompanhou a vida inteira, suscitou grande admiração, mas também serviu como objeto de crítica nos últimos anos do regime, por seu "alheamento dos acontecimentos políticos e dos problemas do reino" (Carvalho, 2007: 227).

Além da paixão pelos estudos e pela leitura, D. Pedro II também adorava escrever. Ao longo da vida escreveu um diário (43 cadernos), em que anotava compromissos e atividades diárias, e também narrava suas viagens no Brasil e no exterior, além dos dias de exílio. Foi intensa a correspondência que mante- 
ve com políticos, artistas e amigos, especialmente com a condessa de Barral. O imperador também produziu poemas e escreveu artigos, como aqueles em que defende o poema Confederação dos Tamoios de Gonçalves de Magalhães do ataque feito por José de Alencar (Carvalho, 2007: 227 et seq.).

Segundo seus biógrafos, desde o início de seu reinado D. Pedro II visou dar uma autonomia cultural ao país, vindo a tornar-se um grande mecenas e incentivador das letras, das artes e da ciência. O Instituto Histórico e Geográfico Brasileiro (IHGB), criado em 1838 nos moldes do Institut Historique de Paris, foi um centro de estudos fundamental no projeto do imperador de fortalecimento da cultura nacional. O IHGB, cujos membros eram a elite econômica e literária fluminense, fomentava a pesquisa literária e pretendia criar uma historiografia brasileira livre do olhar estrangeiro. D. Pedro II financiava a instituição, frequentava as reuniões do grupo no Paço Imperial (em sala cedida por ele) e presidia sessões (Schwarcz, 1998: 126-127).

Segundo Schwarcz (1998), "D. Pedro e a elite política da corte preocupavam-se com o registro e a perpetuação de uma certa memória, mas também com a consolidação de um projeto romântico, para a conformação de uma cultura 'genuinamente nacional"' (p. 127). Em uma de suas primeiras participações no Instituto, o monarca propôs para debate o seguinte tema: "O estudo e a imitação dos poetas românticos promovem ou impedem o desenvolvimento da poesia nacional?", demonstrando inquietar-se com o efeito da assimilação da estética romântica sobre a produção autóctone.

Joaquim Manuel de Macedo, Gonçalves Dias e Francisco Adolfo de Varnhagen, considerado o fundador da historiografia brasileira, faziam parte do grupo de escritores patrocinado pelo imperador com o objetivo de inventariar as "originalidades locais". Pedro II também fomentou a criação de gramáticas e dicionários; interessou-se por pesquisas de etnografia e linguística americana; ajudou diversos cientistas (naturalistas, botânicos, cartógrafos). O desejo de fundação de uma nacionalidade estava ligado a um projeto de consolidação do poder monárquico. $O$ imperador, com sua fama de mecenas, foi comparado a reis e príncipes como Luiz XIV da França e os Médici, na Itália (Schwarcz, 1998: 128 e 131).

TradTerm, 17, 2010, p. 45-66 


\section{O tradutor}

O segundo imperador do Brasil, considerado um dos soberanos mais ilustrados do século, dedicou-se também à tradução, geralmente de poemas e textos religiosos da tradição judaica e da católica. Por ser poliglota e traduzir por prazer, fazia traduções entre vários pares de línguas, nem sempre identificadas nas fontes disponiveis.

Além dos poemas e textos religiosos, que serão objeto de comentários mais detalhados a seguir, traduziu também Prometeu acorrentado, de Ésquilo, colocado em verso pelo barão de Paranapiacaba (Carvalho, 2007), e as Mil e uma noites, do árabe para o português. Sobre o estudo do árabe, D. Pedro II afirma em prefácio a suas traduções de poesias hebraico-provençais, escrito em 1891: "[...] continuei o estudo sério do árabe [...]. E o fiz não só por entendê-lo indispensável a quem deseja aprofundar-se no hebraico como por causa de sua literatura, muito rica e sobremodo interessante" (Loewenstamm, 2002: 45). E complementa, a respeito dos frutos desse aprendizado: "Empreendi, também, a primeira tradução, portuguesa (à vista do original) das Mil e uma noites que, no entanto não está muito adiantada" (Ibidem).

\section{As traduções de narrativas bíblicas}

Apaixonado pela Bíblia, o imperador traduziu narrativas do Antigo Testamento, como os quatro capitulos do Livro de Ruth e fragmentos do Gênesis, dos livros proféticos de Isaías, Jeremias e das Lamentações, bem como dos livros sapienciais de Jó, Cântico dos Cânticos e Salmos. Segundo Stoianoff (2007), depois de abdicar, "traduziu Camões para o hebraico, passou partes do Velho Testamento do hebraico para o latim, dentre elas o Cântico dos Cânticos, Isaías, Lamentações e Jó”. Do Novo Testamento, consta ter vertido os Atos dos Apóstolos (Faingold, 2008; Stoianoff, 2007).

O Livro de Ruth, narrativa do Antigo Testamento com a qual o imperador se encantara desde jovem, é um romance pastoril passado nos antigos campos de Moab, na planície de Jericó. 
Em viagem à Terra Santa, em 1876, D. Pedro II visita a região e se emociona ao lembrar-se da narrativa, por ele traduzida (Faingold, 2008), que busca mostrar os princípios norteadores da comunidade judaica, tendo como personagem principal uma mulher que representa a luta contra a lei do puro e do impuro imposta pelos sacerdotes à época do Império Persa.

A tradução dos quatro capítulos desse livro bíblico feita do hebraico para o latim por D. Pedro II encontra-se no acervo do IHGB. O manuscrito foi oferecido ao instituto pelo Barão de Paranapiacaba, João Carlos de Menezes e Sousa, por intermédio do Conde de Afonso Celso, em sessão realizada em 15 de agosto de 1912. São 11 páginas em que não há comentários ou indicações à tradução, trazendo apenas a indicação "Ruth cap. I, cap. II, cap.3 e cap. IV". O texto em cursivo e de dificil leitura possui algumas rasuras.

Durante a mencionada viagem de 24 dias à Terra Santa, D. Pedro II trabalhou com afinco nas traduções, como relata o historiador Reuven Faingold, especialista em história judaica:

[s]empre achava intervalos para realizar exercícios de tradução com seu mestre de hebraico e sânscrito, o alemão Karl Henning. Horários imprevisiveis e lugares históricos que inspirassem o monarca eram os escolhidos para realizar essas traduções. A primeira tradução dos Atos dos Apóstolos começou depois do almoço às margens do arroio Dhirani e continuou depois de uma animada festa noturna. (Faingold, 2008: 3)

Algumas vezes o imperador examinava lugares históricos mencionados na Bíblia e lamentava não ter, naquele preciso momento, o texto para traduzir ou ler determinadas passagens. Geralmente, o monarca traduzia antes de dormir, mesmo depois de um dia cansativo. Observa Faingold: "Traduzir, traduzir, traduzir! Parece que essa atividade se tornou uma verdadeira obsessão" (2008: 4).

Vale notar que, em suas viagens, D. Pedro II estava sempre acompanhado de algum de seus professores; com eles, aprofundava o estudo de idiomas e realizava traduções, ao que parece, como um exercício individual de aprendizagem.

TradTerm, 17, 2010, p. 45-66 
Em 1891, o imperador traduziu para o francês poesias (cânticos ou piouts) hebraico-provençais do Ritual Israelita Comtadin, publicadas no mesmo ano por uma editora france$\mathrm{sa}^{3}$, juntamente com um prefácio também de D. Pedro II, escrito em francês. Tanto as traduções como o ensaio prefacial estão disponiveis no apêndice do livro O Hebraista no trono do Brasil, de Kurt Loewenstamm (2002), em tradução para o português feita por Affonso E. de Taunay. Nesse prefácio, o monarca afirma ter realizado uma obra modesta, mas demonstra ter uma expectativa positiva em relação à recepção do trabalho; julga que este será bem recebido pelo público por razões de interesse histórico: o centenário de anexação do Comtat Venaissin (Avignon, Carpentras, L'Isle, Cavaillon) à França. Essa região, que serviu de refúgio a israelitas fugidos de perseguições religiosas desde a Inquisição, usava um dialeto com elementos do antigo provençal, do hebraico e do francês. O imperador declara ainda que seus estudos hebraicos têm por objetivo conhecer melhor a história e a literatura dos judeus, sobretudo a poesia e os profetas, assim como as origens do Cristianismo.

\section{O livro de poemas e traduções}

D. Pedro II escreveu e traduziu poemas, na maioria sonetos. Em sua homenagem, os netos D. Pedro e D. Luiz, filhos da princesa Isabel, organizaram um livro com 10 sonetos de autoria do avô e traduções para o português feitas por ele de 26 poemas, duas canções, duas pequenas passagens da Divina Comédia e sete textos religiosos em latim. A edição é parcialmente bilingue, visto que em alguns casos o texto traduzido vem acompanhado do original. A tarefa de composição e impressão foi supervisionada pelo aio de Suas Altezas, barão Ramiz Galvão. No livro de 102 páginas, impresso pela Typografia do Correio Imperial, em Petrópolis, em 1889, disponivel no acervo do IHGB, não há prefácio(s) ou comentários às traduções.

Poésies Hebraico-Provençales du Rituel Israélite-Comtadin. Traduites et transcrites par S. M. Dom Pedro II D’Alcantara, Empereur du Brésil. Seguin Frères, Emprimeurs-Editeurs. Avignon, 1891. 
Na primeira parte do livro, com o subtítulo SONETOS, são apresentados 10 sonetos de autoria do imperador. A seguir vêm as traduções, com o subtítulo VERSÕES. Relacionamos abaixo os títulos das traduções com o nome do autor, assinalando entre parênteses quando o original consta ao lado da tradução. Cabe ressaltar que, em alguns casos, não foi possivel obter mais informações sobre os autores ou os próprios poemas.

- Episódio do Conde Ugolino, Divina Comédia, Dante Alighieri

- Episódio de Francisca de Rimini, Divina Comédia, Dante Alighieri

- Ode "Cinco de Maio", tradução de "Il Cinque Maggio", de Alessandro Manzoni

- "A canção dos latinos", traduzida da versão em italiano "La Canzone dei Latini" de canção provençal feita por Leonida Olivari (acompanhada da versão em italiano)

- Soneto "A Aloys Blondel", tradução de "A Aloys Blondel", de François Coppée (acompanhado do original francês)

- Soneto de Félix Anvers, intitulado simplesmente "Sonnet" (acompanhado do original francês)

- Poema "A Passiflora", tradução de "La Passiflore", da Condessa de Chambrun (acompanhado do original francês)

- Soneto de D. Mon, intitulado simplesmente "Sonnet" (acompanhado do original francês)

- "Soneto a Coquelin", tradução de "Sonnet a Coquelin", de Jean Richepin, (acompanhado do original francês)

- Soneto de Sully Prudhomme, intitulado simplesmente "Sonnet" (acompanhado do original francês, cujo início é "Il est tard...")

- Soneto de Sully Prudhomme (acompanhado do original francês, cujo início é "La Grande Ourse...")

- Soneto "O magistrado", tradução de "Le Magistrat", de Rigaud, presidente do Tribunal da Relação d'Aix, que o escreveu em homenagem a esse tribunal (acompanhado do original francês)

- Soneto "A terra natal", tradução de "Le sol natal", de Rigaud, escrito em homenagem à aldeia de Pourrières (acompanhado do original francês) 
- Soneto do General Carnot intitulado simplesmente "Sonnet" (acompanhado do original francês)

- Soneto "O beija-flor", tradução de "Le colibri", de Leconte de Lisle (acompanhado do original francês)

- Soneto "A la mignarda", tradução de "A la Mignarde", de Rigaud (acompanhado do original francês)

- "O Adeus", tradução de "Les Adieux", do Journal l'lllustration de dezembro de 1887 (acompanhado do original francês)

- Soneto de Helena Vacaresco, intitulado simplesmente "Sonnet" (há duas traduções diferentes do mesmo soneto, acompanhadas do original francês)

- Poema de seis estrofes "Cantiga de Nadaud", tradução de "Chanson de Nadaud", escrito para servir de prefácio às Canções de Béranger (acompanhado do original francês)

- Poema "O besouro", tradução de "Le Hanneton", de Gustave Nadaud (acompanhado do original francês)

- Versos de Gustavo Nadaud, tradução de "Vers de Gustave Nadaud", escritos sob o retrato da Duquesa Colonna pintado por ela mesma (acompanhados do original francês)

- Poema "A borboleta e a flor", tradução de "Le papillon et la fleur", de Victor Hugo (acompanhado do original francês)

- Estâncias (estrofes) em homenagem a S. M. o Senhor D. Pedro de Alcântara, escritas por Alfredo Theulot a bordo do navio Congo (acompanhado do original francês)

- Poema "A sua majestade Dom Pedro II", tradução dos versos do comandante Moreau (acompanhado do original francês)

- Poema dedicado a Chapelle e Bachaumont na sua viagem pela Provença (acompanhado do original francês)

- Versos d'Ernesto Heller à morte do poeta Dranmor (Schmidt) (acompanhados do original alemão)

- Epigrama feito pelo Dr. Dodderige (acompanhado do original inglês)

- Poema "O choro d'uma alma perdida", tradução de "The cry of a lost soul", de John Whittier 
- Poema "O canto do siciliano: El rei Roberto da Sicília", tradução de "The Sicilian's Tale: King Robert of Sicily", de Henry Longfellow

- Poema "Aos mortos de Sahati", tradução de "Ai morti di Sahati", de Luigi Nobrega (acompanhado do original italiano)

- Cantos religiosos "Miserere" (Psalmo L.), "Oh Salutaris Hostia", "Panis Angelicus", "Ave, verum", "Pange lingua", "Vexilla regis", "Stabat mater".

A partir da relação de traduções incluídas no volume, algumas observações podem ser feitas com respeito à escolha de autores e temas por parte do monarca-tradutor. D. Pedro traduziu desde grandes poetas e escritores, como Dante, Victor Hugo e Longfellow, até autores menos conhecidos que particularmente lhe agradavam, além de cantos religiosos tradicionais do catolicismo. Um caso particularmente interessante é o do comandante Moreau, do navio Congo, que trouxe o imperador de volta ao Brasil após viagem à Europa em 1888. Em homenagem ao imperador, o comandante escreveu em francês um pequeno poema, que foi traduzido pelo homenageado ("A Sua Majestade") e publicado na antologia compilada pelos netos.

Em relação às traduções de textos de escritores e poetas consagrados, as escolhas de D. Pedro II pareciam ocorrer por predileção estética e razões pessoais.

Alessandro Manzoni (1785-1873), um dos grandes nomes da literatura italiana, era muito admirado por D. Pedro II, que dele traduziu a ode Il cinque maggio. Em sua primeira viagem ao exterior, em 1871, o imperador fez questão de conhecer o poeta e escritor, sobre quem afirmou: "Os séculos recordarão Alexandre Manzoni, enquanto os anos farão desaparecer a lembrança de D. Pedro d'Alcântara" (Carvalho, 2007: 150). O poema que transpôs para o português é uma homenagem a Napoleão, morto no exílio em cinco de maio de 1821. Celebrado como herói, conquistador que cruzou dos Alpes às pirâmides, de um a outro mar, o Napoleão de Manzoni talvez tenha inspirado o soberano brasileiro pela sua estatura política ou despertado empatia ou afinidades. Vale observar, entretanto, que o Pedro II que a história nos apresenta é bem diferente de Napoleão: um imperador de 
vocação democrática, "que renunciou à concentração de poderes em suas mãos" (Olivieri, 1999: 24), deixando seus ministérios governarem sem maiores interferências; um estadista "que se limitava a cumprir suas obrigações, conformado com as formalidades do seu cargo" (ibidem). De qualquer forma, na ausência de evidências para corroborar a hipótese de motivações políticas na tradução do poema de Manzoni, o que se destaca são o respeito e a admiração dedicados a um grande poeta por um monarca amante das letras que parece acreditar - pelo menos é o que sua retórica sugere - que a obra do artista sobrepujará e será mais duradoura do que a do governante.

Encontra-se também no livro a tradução do poema "The cry of a lost soul", do poeta quaker John Whittier (1807-1892). Abolicionista, Whittier, que se tornou um admirador do imperador ao conhecer seu posicionamento antiescravista, escreveu esse poema inspirado pela Lei do Ventre Livre. Também nesse caso existe uma possibilidade de a escolha ter tido alguma motivação política, mas não há maiores evidências disso em textos como, por exemplo, prefácios ou cartas. Tampouco as atitudes do soberano com relação à escravatura permitem inferir tais motivações. Segundo Olivieri (1999), o imperador, ao assinar em 1850 - sob pressão dos ingleses - a Lei Eusébio de Queirós, que proibia o tráfico interatlântico de escravos,

fazia a sua primeira manifestação pública contra a escravidão. Homem culto e informado, dom Pedro II repudiava o trabalho escravo e o considerava uma vergonha nacional. Entretanto, seu empenho pessoal em resolver a questão sempre foi pequeno. (p. 44)

Com respeito ao movimento abolicionista, aparentemente o imperador esteve, na maior parte do tempo, alheio ao seu fortalecimento, embora fosse favorável a ele, e quando agiu, "foi tímido e lento diante das exigências da época", segundo relata Olivieri (1999: 43), que complementa: "É mínima a participação de Pedro II no processo que resultou na abolição da escravatura" (p. 43). No entanto, em 1888, em temporada na Europa para tratamento de saúde, ao saber da promulgação da Lei Áurea teria dito: "Grande povo! Grande povo!" (Carvalho, 2007: 203). 
Outro autor traduzido por Pedro II foi Henry Longfellow (1807-1882), importante poeta americano cuja tradução da $D i-$ vina Comédia, de Dante Alighieri, tornou-se referência no mundo erudito da época. Seu poema "The Sicilian's tale: King Robert of Sicily", que louva as virtudes da humildade do rei da Sicília, recebeu uma tradução em português pelo imperador brasileiro, que se identificava com o rei homenageado pelo fato de sua ascendência Bourbon provir do reino das Duas Sicílias. Por meio do Reverendo James Cooley Fletcher, que era secretário da legação americana no Brasil, Longfellow soube que o imperador brasileiro era um grande admirador seu; passaram a corresponderse e tornaram-se amigos. O imperador o visitou quando esteve nos Estados Unidos em 1876 para assistir às festas do centenário da independência do país (Longfellow House Bulletin, 2000).

Respeitado por sua erudição em todo o mundo intelectual da época, o imperador recebeu um grande elogio de Longfellow, que afirmou ter-se sentido honrado ao receber em 1864 a tradução feita por D. Pedro II do poema sobre o rei da Sicília, trabalho que considerou fiel e muito bem realizado.

I have had the honor of receiving your Majesty's beautiful version of 'King Robert of Sicily,' and beg leave to offer my best acknowledgements and thanks for this mark of consideration. The translation is very faithful and very successful. The double rhymes give a new grace to the narrative, and the old Legend sounds very musical in the soft accents of the Portuguese. Permit me to express my sense of the honor done me, and to subscribe myself. (Longfellow, 2000)

Essa opinião, no entanto, contrasta com a de José Murilo de Carvalho, biógrafo de D. Pedro II, que de modo geral considera as traduções do monarca "sempre excessivamente literais, sem grande valor literário" (Carvalho, 2007: 232).

O imperador também tinha enorme admiração pelo célebre escritor Victor Hugo (1802-1885), com quem se encontrou em Paris em 1887 após certa resistência de Hugo, que era antimonarquista. Do autor de Les Misérables, traduziu "Le papillon et la fleur", poema sem aparentes conotações políticas, 
assim como os que selecionou da obra dos parnasianos franceses Leconte de Lisle (1818-1894) e Sully Prudhomme (1839-1907).

Ao final do livro há traduções de cantos ou orações da tradição católica. Os originais em latim não são apresentados. O Salmo 51 (Salmo L-50 em numeração romana), conhecido como Miserere, enseja uma mensagem de humildade e arrependimento. "Oh Salutaris Hostia", "Panis Angelicus" (penúltima estrofe de Sacris Solemniis) e "Pange Lingua" foram escritos por São Tomás de Aquino. "Ave, verum" é uma poesia religiosa medieval de autor anônimo do século XIV. "Vexilla Regis" foi composta, no século VI, pelo poeta e bispo da Igreja Católica São Venâncio Fortunato. "Stabat Mater" é um poema do século XIII atribuído ao frade franciscano Jacopone da Todi.

Empreendendo uma análise microtextual de alguns poemas da antologia (v. Anexo), é possivel perceber que D. Pedro II tinha uma preocupação formal, buscando seguir um contrato métrico e um esquema de rimas. Foram examinados um soneto de Felix Anvers; "Le colibri", de Leconte de Lisle; "The Sicilian's tale: King Robert of Sicily", de Longfellow; e "The cry of a lost soul", de Whittier ${ }^{4}$.

O soneto original de Anvers está em dodecassílabos alexandrinos, de acordo com padrão clássico da poesia francesa, com o seguinte esquema rímico: abab, baab, ccd, eed. O imperador traduziu-o para o português em decassílabos, seguindo um esquema ligeiramente diferente: abab, baab, ccb, ddb.

Os poemas de Longfellow e Whittier, escritos em inglês, língua em que não há uma metrificação silábica, as traduções foram surpreendentemente feitas em alexandrinos, não em decassilabos, que são considerados os equivalentes mais próximos dos pentâmetros (versos de cinco pés) do inglês. Nesses casos, o imperador seguiu o padrão erudito característico de sua época: a valorização da cultura francesa e de seu modelo literário. No que diz respeito à rima, o poema de Whittier é composto de 15 tercetos com rimas aaa, bbb, ccc e assim sucessivamente,

4 Agradecemos ao Prof. Paulo Henriques Britto, da PUC-Rio, especialista em tradução de poesia, as orientações com respeito à análise dos poemas. 
com apenas três repetições. A versão em português mantém o mesmo número de tercetos e de repetições, embora estas ocorram em estrofes distintas. O extenso "Canto do siciliano", de Longfellow, traz rimas seguidas, de duas em duas: aa, bb, cc etc. $\mathrm{Na}$ tradução, o terceiro verso ficou isolado sem rima, e ao final do primeiro bloco de versos, há três seguidos com a mesma rima $(18,19,20)$. Além disso, enquanto o original apresenta 22 versos nesse bloco de abertura, a tradução traz 20 versos.

Já no caso do soneto Le colibri, de Leconte de Lisle, em versos decassílabos, a regularidade silábica não se mantém na tradução; intitulada $O$ beija-flor, a versão do imperador foi feita predominantemente em decassílabos, mas seis dos versos desviam-se dessa métrica, apresentando variações de uma ou duas sílabas.

\section{Considerações finais}

A atividade tradutória do imperador pode ser compreendida como complementar ao seu processo de aquisição de conhecimento, sobretudo de cultura literária e religiosa, tanto católica quanto judaica. D. Pedro II não parece ter tido, em relação à tradução, um objetivo político de difusão de ideias, obras, autores ou culturas estrangeiras; tampouco uma proposta de transpor para o português textos originalmente produzidos em outros idiomas, pois, como vimos, traduziu do hebraico para o latim e para o francês. Suas traduções eram realizadas de acordo com seu gosto pessoal e com o objeto de seu estudo ou admiração em um dado momento.

Embora sua atividade tradutória esteja inserida em um contexto mais pessoal do que político, as traduções que D. Pedro II realizou a partir do hebraico adquiriram relevância perante historiadores da cultura judaica, que reverenciam a atuação do imperador na preservação da memória do povo judeu. Pesquisadores como Shlomo Haramati, da Universidade Hebraica de Jerusalém, ressaltam a importância do projeto tradutório de D. Pedro II e o consideram um grande amigo do povo judeu pelo resgate de tradições que promoveu. Uma medida dessa importância pode ser percebida no seguinte comentário atribuído a

TradTerm, 17, 2010, p. 45-66 
Nahum Sokolov, decano dos jornalistas e escritores israelenses, acerca da tradução para francês das poesias hebraico-provençais realizada pelo imperador:

Nenhum de nossos homens de letras teve a idéia de salvar do esquecimento e da perda estas peças do folclore judaico, até que veio o imperador brasileiro e coletou-as, interpretou-as, traduziu-as e publicou-as, com total fidelidade aos originais. (Haramati, s.d.)

\section{Referências Bibliográficas}

ALCÂNTARA, D. Pedro de (1989) Poesias (originaes e traduções) de S. M. o Senhor D. Pedro II. Homenagem de seus netos. Petrópolis: Tipografia do Correio Imperial.

CARVAlHO, José Murilo de (2007) D. Pedro II. São Paulo: Companhia das Letras.

FAINGOLD, Reuven (2008) "D. Pedro II, manuscritos hebraicos e os orientalistas de São Petesburgo". Arquivo Maaravi - Revista Digital de Estudos Judaicos da UFMG n 2, (Torah) vol. 1, abril 2008, pp. 18. Disponivel em: http://www.reuvenfaingold.com. Acesso em 10 jul. 2009.

HARAMATI, Schlomo (s.d.). "D. Pedro II falava fluentemente hebraico". Tradução de Ephraim Knaan e Moshé Waldmann. Disponivel em: http://hebreu.blogspot.com. Postado em 29 nov. 2008. Acesso em 10 jul. 2009.

LOEWENSTAMM, Kurt (2002) Imperador D. Pedro II: O Hebraísta no Trono do Brasil. São Paulo: Centauro.

LONGFELLOW House Bulletin (2000) vol. 4, n. 2. Disponivel em: http:/ /www.longfellowfriends.org/bulletins/Vol4No2.pdf. Acesso em 10 jul. 2009.

OLIVIERI, Antonio Carlos (1999) Dom Pedro II, Imperador do Brasil. São Paulo: Callis.

SCHWARCZ, Lilia Moritz (1998) As barbas do imperador: D. Pedro II, um monarca nos trópicos. São Paulo: Companhia das Letras.

STOIANOFF, Raquel. "Um amigo chamado Pedro". Disponivel em http:/ /www.deolhonamidia.org.br/Publicacoes/Arquivo.asp?PaginaAtual =7. Acesso em 10 jul. 2009 . 
60

\section{ANEXO}

\section{Sonnet}

(Félix Anvers)

Mon âme a son secret, ma vie a son mystère;

Un éternel amour en un instant conçu;

Le mal est sans espoir, aussi j'ai dû le taire,

Et celle qui l'a fait n'en a jamais rien su.

Hélas! J'aurai passé près d'elle inaperçu, Toujours à ses côtés et pourtant solitaire, Et j'aurai, jusqu'au bout, fini mon temps sur terre, N'osant rien demander et n'ayant rien reçu!

Pour elle, quoique Dieu l'ait faite douce et tendre Elle ira son chemin, distraite et sans entendre Ce murmure d'amour élevé sur ses pas.

A l'austère devoir pieusement fidèle, Elle dira, lisant ces vers tout remplis d'elle:

"Quelle est donc cette femme ? " et ne comprendra pas.

\section{Soneto}

(Tradução de D. Pedro II)

Segredo d'alma, da existencia arcano, Eterno amor num instante concebido, Mal sem esperança, occulto a ente humano, E nunca de quem fê-lo conhecido.

Ai! Perto d'ella desapercebido Sempre a seu lado, e só, cruel engano, $\mathrm{Na}$ terra gastarei meu ser insano Nada ousando pedir e havendo tido! 
Se Deus a fez tão doce e carinhosa, Contudo anda inattenta e descuidosa Do murmurio d'amor que a tem seguido.

Piamente ao crú dever sempre fiel

Dirá lendo a poesia, seu painel:

"Que mulher é?" Sem tê-lo comprehendido.

\section{Le colibri}

(Leconte de Lisle)

Le vert colibri, le roi des collines, Voyant la rosée et le soleil clair Luire dans son nid tissé d'herbes fines, Comme un frais rayon s'échappe dans l'air.

Il se hâte et vole aux sources voisines Où les bambous font le bruit de la mer, Où l'açoka rouge, aux odeurs divines, S'ouvre et porte au cœur un humide éclair.

Vers la fleur dorée il descend, se pose, Et boit tant d'amour dans la coupe rose, Qu'il meurt, ne sachant s'il l'a pu tarir.

Sur ta lèvre pure, ô ma bien-aimée, Telle aussi mon âme eût voulu mourir Du premier baiser qui l'a parfumée!

\section{O beija-flor}

(Tradução de D. Pedro II)

O verde beija-flor, rei das colinas

Vendo o rocio e o sol brilhante

Luzir no ninho, trança d'ervas finas,

Qual fresco raio vai-se pelo ar distante.

TradTerm, 17, 2010, p. 45-66 
62

Rápido voa ao manancial vizinho,

Onde os bambus sussurram como o mar,

Onde o açoká rubro, em cheiros de carinho,

Abre, e eis no peito úmido a fuzilar.

Desce sobre a áurea flor a repousar,

$\mathrm{E}$ em rósea taça amor a inebriar,

E morre não sabendo se a pode esgotar!

Em teus lábios tão puros, minha amada, Tal minha alma quisera terminar,

Só do primeiro beijo perfumada!

\section{The cry of a lost soul}

(John Whittier)

In that black forest, where, when day is done, With a snake's stillness glides the Amazon Darkly from sunset to the rising sun, A cry, as of the pained heart of the wood, The long, despairing moan of solitude And darkness and the absence of all good, Startles the traveller, with a sound so drear, So full of hopeless agony and fear,

His heart stands still and listens like his ear. The guide, as if he heard a dead-bell toll, Starts, drops his oar against the gunwale's thole, Crosses himself, and whispers, "A lost soul!" "No, Senor, not a bird. I know it well,It is the pained soul of some infidel Or cursed heretic that cries from hell. "Poor fool! with hope still mocking his despair, He wanders, shrieking on the midnight air For human pity and for Christian prayer. "Saints strike him dumb! Our Holy Mother hath No prayer for him who, sinning unto death, Burns always in the furnace of God's wrath!"

TRadTerm, 17, 2010, p. 45-66 
Thus to the baptized pagan's cruel lie, Lending new horror to that mournful cry, The voyager listens, making no reply. Dim burns the boat-lamp: shadows deepen round, From giant trees with snake-like creepers wound, And the black water glides without a sound. But in the traveller's heart a secret sense Of nature plastic to benign intents, And an eternal good in Providence, Lifts to the starry calm of heaven his eyes; And lo! rebuking all earth's ominous cries, The Cross of pardon lights the tropic skies! "Father of all!" he urges his strong plea, "Thou lovest all: Thy erring child may be Lost to himself, but never lost to Thee! "All souls are Thine; the wings of morning bear None from that Presence which is everywhere, Nor hell itself can hide, for Thou art there. "Through sins of sense, perversities of will, Through doubt and pain, through guilt and shame and ill, Thy pitying eye is on Thy creature still.

"Wilt thou not make, Eternal Source and Goal! In Thy long years, life's broken circle whole, And change to praise the cry of a lost soul?"

\section{O choro d'uma alma perdida}

(Tradução de D. Pedro II)

No mato escuro, aonde, o dia já ausente, Deslisa-se o Amazonas, qual uma serpente, Do pôr do Sol á aurora tenebrosamente,

Como d'alma penada na floresta errante, Chôro extenso, gemido d'ermo cruciante, E das trevas, o bem d'ali então distante,

Tanto abala o viajôr com o horrido sonido 
De angustia e de terror, que todo combalido Lhe pára o coração, e escuta commovido.

Qual ao dobre d'um sino, o guia estremecendo Larga o remo na borda, e logo se benzendo, Diz baixo: "Alma perdida! Eu bem a comprehendo.

"Não é pássaro, não Senhor; é algum damnado "Infiel ou herege ha muito excommungado, "Do inferno a chorar em chammas abrazado.

"Pobre louco! Inda a esperança os males enganando, "Vaguêa á meia noite e em gritos, suspirando, "Vae dos christãos piedade e rezas implorando.

"Santos, emmudecei-o! Oh! Santa Mãe, não valha "Teu rôgo a quem penando até ver a mortalha "Da ira de Deus arde sempre na fornalha!

Do pagão a cruel mentira ao baptisado Augmentando o horror do chôro angustiado, $\mathrm{O}$ viajante escuta, e fica-se calado.

Mal arde a luz no barco; á roda a escuridão Do arvoredo e cipós formando um turbilhão, $\mathrm{E}$ as águas sem rumor negras correndo vão!

Porem ao viajante occulto sentimento De como a natureza é boa em seu intento, $\mathrm{E}$ Deus ao beneficio eterno sempre attento,

Ergue os olhos aos Ceos serenos, luminosos De astros mil tropicaes, e os gritos ominosos Brilha a cruz do perdão, - e ei-los harmoniosos.

"Pae de todos", exclama em fervida oração, "Todos amas: teu filho em peregrinação "A si pode perder-se, a ti não pode não! 
"As almas tuas são, o ar da manhã não traz "Longe uma só do Sêr que em toda parte jaz, "Nem mesmo a esconde o inferno; pois ali estás.

"Atravez do peccado e da perversidade "Dos crimes e vergonhas, dores e maldade, "A tua creatura inda olhas com piedade.

"Principio e Fim Eterno, em tua eterna vida "Não hás de, da existência a trama reurdida, "Mudar em hymno o choro d'uma alma perdida.

\section{The sicilian's tale: king Robert of Sicily ${ }^{5}$}

(Henry W. Longfellow)

Robert of Sicily, brother of Pope Urbane And Valmond, Emperor of Allemaine, Apparelled in magnificent attire, With retinue of many a knight and squire, On St. John's eve, at vespers, proudly sat And heard the priests chant the Magnificat, And as he listened, o'er and o'er again Repeated, like a burden or refrain, He caught the words, "Deposuit potentes De sede, et exaltavit humiles;"

And slowly lifting up his kingly head He to a learned clerk beside him said, "What mean these words?" The clerk made answer meet, "He has put down the mighty from their seat, And has exalted them of low degree."

Thereat King Robert muttered scornfully, "'T is well that such seditious words are sung Only by priests and in the Latin tongue; For unto priests and people be it known,

5 Reproduzimos apenas o primeiro bloco de versos desse longo poema.

TradTerm, 17, 2010, p. 45-66 
66

There is no power can push me from my throne!" And leaning back, he yawned and fell asleep, Lulled by the chant monotonous and deep.

\section{O canto do siciliano: el rei Roberto da Sicília}

(Tradução de D. Pedro II)

Roberto de Sicilia, irmão do Papa Urbano, De Valmundo tambem, Imperador Germano, De muitos cavalleiros nobres rodeado, Vesp'ras de São João, ufano se assentava, Ouvindo repetir, a modo de bordão, Deposuit potentes de sede - e o deão, Sem pausa, - et exaltavit humiles - dizer, Começa a real cabeça apenas a erguer, E diz a um douto padre junto do seu lado: Que palavras são estas? Bom significado Logo o padre lhes dá; responde: "Os poderosos Depõe Elle da Sede e exalta os humildosos. Então El Rei Roberto altivo resmonêa:

"Palavras de motim, que, em bem, só gargantêa "O padre, e na latina língua não s'entendem, "Que já padres e povo, ha muito, comprehendem, "Que nenhum poder basta a m'expulsar do throno." Recosta-se, boceja, e cae em grave somno, Embalado do canto surdo e monotôno. 